\title{
A PRECARIZACÃO DO TRABALHO E A PRODUÇÃO DE ACIDENTES NA COLHEITA DE ÁRVORES
}

\author{
Ada Ávila Assunção* \\ Guilherme Ribeiro Camara **
}

\begin{abstract}
A indústria florestal apresenta as maiores taxas de mortalidade associada ao trabalho no mundo, apesar da introdução da mecanização no setor. Neste artigo, foram estudados os documentos da Comissão Parlamentar de Inquérito instituída para verificar os acidentes fatais ocorridos em Minas Gerais. Analisou-se o processo de trabalho realizado pelas equipes de corte de árvores de uma empresa do setor de extrativismo vegetal e constatou-se que o conhecimento acumulado quanto aos fatores de risco de acidentes nesse setor não orientou a transformação das situações de trabalho. O momento da derrubada de árvores e os riscos consequentes de ser "atingido por" são as principais causas dos acidentes e motivaram a demanda do estudo, sendo coerentes com a descrição encontrada na literatura. As relações de trabalho precarizadas predominam no setor. Os autores associam a manutenção da exposição aos riscos à terceirização crescente, concentrada nas fases da produção, reconhecidas como perigosas.

PALAVRAS-Chave: extrativismo, acidentes de trabalho, precarização, saúde do trabalhador
\end{abstract}

A importância e as potencialidades produtivas do setor florestal no Brasil se apresentam em números expressivos: esse setor contribui com cerca de 5\% na formação do PIB Nacional e com 8\% das exportações, sendo responsável por 1,6 milhões de empregos diretos e 5,6 milhões de empregos indiretos. Beneficia-se de uma enorme diversidade biológica, com 6,4 milhões de hectares de florestas plantadas. Nesse setor, destacamse os estados do Pará e de Minas Gerais, sendo esse último um dos principais produtores na silvicultura (Carvalho et al., 2005).

$\mathrm{O}$ segmento da madeira industrial utiliza exclusivamente madeira de florestas plantadas (eucalipto e pínus). Segundo a Associação Brasileira de Papel e Celulose (BRACELPA, 2010), o setor conta com 222 empresas em 494 municípi-

* Médica. Doutora em Ergonomia. Professora do Departamento de Medicina Preventiva e Social da Faculdade de Medicina da Universidade Federal de Minas Gerais. Pesquisadora do CNPq.

Av. Alfredo Balena 190 sala 707. Santa Efigênia. Cep: 30130100. Belo Horizonte - Minas Gerais - Brasil. adavila@medicina.ufmg.br

* * Médico do trabalho. Mestre em Saúde Pública. Professor da Faculdade de Medicina do Vale do Aço (FAMEVAÇO). Guilherme.camara@usiminas.com os, localizados em 18 estados, perfazendo 2,2 milhões de hectares de área plantada para fins industriais. No referido segmento, registram-se 115 mil empregos diretos (68 mil na indústria e 47 mil nas florestas) e 575 mil empregos indiretos.

No entanto, as potencialidades econômicas convivem com alta prevalência de acidentes de trabalho fatais, o que faz com que o setor seja considerado um dos mais perigosos mundialmente. Diante desses riscos, foram criadas medidas de segurança e de proteção exequíveis para os trabalhadores (Bentley et al., 2005; European Agency for Safety and Health at Work, 2008; Potoènik, 2009).

Neste artigo, examina-se como mudanças técnico-organizacionais são geradas em empresas florestais que praticam a terceirização da produção e de que maneira tais mudanças interferem na segurança do trabalho e no risco de acidentes.

Em que pesem as lacunas nas estatísticas no que diz respeito a acidentes ou doenças ocupacionais no Brasil, demandas sociais expuseram a precariedade das condições de emprego e de trabalho no âmbito de uma Comissão Parla- 
mentar de Inquérito (CPI) na Assembleia Legislativa do estado de Minas Gerais (ALMG, 2002) que investigou as denúncias sobre acidentes fatais envolvendo operadores florestais. Os documentos das empresas, dos sindicatos e da Federação dos Trabalhadores nas Indústrias Extrativas do Estado de Minas Gerais (FTIEMG), do Ministério do Trabalho e Emprego e da produção acadêmica compuseram o relatório final da CPI e foram examinados pelos autores do presente artigo.

O artigo apresenta revisão bibliográfica, exposição teórica e descrição de resultados obtidos de pesquisas epidemiológicas sobre acidentes no setor, exposição de resultados da pesquisa de Camara (2004), que focalizou a organização do trabalho em uma empresa que contrata uma terceira para as operações florestais, e uma análise de dados documentais obtidos do relatório da CPI citada anteriormente.

A abordagem adotada permitiu explorar os componentes de uma situação complexa, na qual se identificam duas zonas críticas de segurança no trabalho: (1) as condições geográficas agressivas e a exuberância das florestas, que configuram o espaço de trabalho dos operadores florestais; (2) as metas colocadas, que negligenciam a segurança e situações deterioradas, resultantes da gestão da produção, no contexto da flexibilização do trabalho, lembrando que a maioria dos postos de trabalho flexível é definida como precária.

No contexto da flexibilização das relações de trabalho, a terceirização, ou seja, a transferência de determinados serviços para terceiros, tem permitido outras formas de contratação que substituem o emprego formal, regulamentado e relativamente estável (Antunes, 2007). O emprego precário é um construto sociológico que designa a perda das regulações sustentadas pelas relações de contrato padrão do emprego típico, ${ }^{1}$ tornando os trabalhadores mais vulneráveis.

${ }^{1}$ Contrato de trabalho-padrão ou emprego típico é definido por Galeazzi (2007, p.84) como aquele realizado para um único empregador, geralmente por período indefinido, acordado através de contrato de trabalho entre o empregador e o empregado, exercido em local definido pelo primeiro, com tarefas definidas e exercidas de modo contínuo, com regime de jornada integral e plenamente amparado pela legislação vigente que rege o trabalho subordinado.
A situação do emprego precário expressa múltiplas facetas com implicações sobre a saúde das pessoas: vulnerabilidade do contrato e do vínculo, fraca ou nenhuma proteção social, baixo nível de renda, exposição às elevadas cargas de trabalho e ao trabalho perigoso (Benavides et al., 2006; Fabiano et al., 2008). Tais facetas são próprias às situações de não-regulamentação do trabalho assalariado, uma vez enfraquecidos ou rompidos os compromissos entre o capital, o Estado e os direitos conquistados pelos trabalhadores (Rivero, 2009).

\section{O PROCESSO DE TRABALHO E OS ACIDEN- TES NA COLHEITA DE ÁRVORES}

O setor florestal integra, além dos produtos madeireiros, produtos florestais não-madeireiros, sendo eles: (1) produtos para o consumo humano (alimentos, bebidas, plantas medicinais e extratos, por exemplo: frutas, bagas, nozes, mel, fungos, entre outros); (2) farelos e forragem (campos para pastagem) e; (3) outros produtos nãomadeireiros, tais como cortiça, resinas, taninos, extratos industriais, plantas ornamentais, musgos, samambaias, óleos essenciais etc. (Carvalho et al., 2005).

O processo produtivo de colheita de madeira, em tese, divide-se em diversas fases: plantio, roçamento, derrubada, traçamento, empilhamento, baldeio, carregamento e transporte. O roçamento é a fase de preparação das áreas que posteriormente receberão as equipes de corte. São retirados os feixes de galhos espalhados no terreno e é feita a preparação da zona em torno da árvore que será cortada. As irregularidades no terreno são reparadas, visando a facilitar o trabalho do corte e melhorar a segurança na área.

Após a derrubada da árvore, ocorrerá o corte do tronco em toretes, fase denominada traçamento, e, depois, o empilhamento, iniciado quando equipes especializadas fazem pilhas da madeira já cortada. Finalizado o empilhamento, inicia-se o baldeio das pilhas até a margem da 
estrada, para facilitar o transporte pelos caminhões. A fase de carregamento consiste na colocação das pilhas de toretes em caminhões, visando ao transporte e à locomoção até o pátio das plantas industriais, nas quais será beneficiada essa matéria-prima (Camara, 2004).

Razões econômicas podem explicar o uso de motosserras na fase da colheita das árvores, pois se evitam investimentos em equipamentos mecânicos do tipo de máquina com cabine. Adicionalmente, em diferentes países, razões geográficas relacionadas ao tipo de relevo dificultam o acesso das máquinas com cabine, explicando, também, a utilização do equipamento manual (Bentley et al., 2005). As operações com a motosserra são frequentemente destinadas aos trabalhadores terceirizados.

A colheita, na Nova Zelândia, implica deslocamento em terreno íngreme, com vários tipos de solo e de condições climáticas adversas, agravando o risco de escorregões, tropeções e quedas. Análise dos dados relativos ao período de 1985 a 1991 evidenciou que 17,5\% de tempo perdido de trabalho foram associados a lesões geradas por acidentes no nível do solo. Tais lesões resultaram na perda de 2.870 dias durante um período de seis anos (Bentley et al. 2002).

A fase de derrubada da árvore concentrou os acidentes de trabalho na indústria florestal da Indonésia, no período de 1974 a 1990 (Strehlke, 1993). As zonas de risco identificadas foram as seguintes: derrubadas que acontecem na própria área de trabalho (no espaço onde se encontra o operador e o seu ajudante), numa distância correspondente àquela da altura de duas árvores, veículos inadequadamente sinalizados ou com escassos recursos para a comunicação, veículos trafegando em áreas onde as atividades de derrubada estejam acontecendo e técnica inadequada de derrubada, sendo citado o "efeito dominó". A técnica denominada "efeito dominó" consiste em redirecionar o corte de uma árvore para derrubar outra que ficou "enroscada". Embora reconhecidamente arriscada, pois não é possível o controle completo da direção da queda da árvore, essa técnica consiste numa prática bastante comum no campo (Camara, 2004).

Em um estudo realizado em Minas Gerais, que envolveu trabalhadores em atividades de corte manual, informou-se que a maioria (40\%) dos acidentes acontece no momento da derrubada com motosserra. Entre os entrevistados, $89,6 \%$ consideram o seu trabalho perigoso e $72,4 \%$ indicaram a derrubada de árvores como zona crítica de acidentes. Ainda na colheita, são registrados acidentes ocasionados pela queda de galhos, de troncos ou de árvores inteiras em virtude da força do vento ou das tempestades. Apesar de terem recebido treinamento formal, 19,5\% negaram experiência com o uso do equipamento, e $44,8 \%$ dos entrevistados já sofreram pelo menos um acidente de trabalho (Santana; Malinovski, 2002).

Potoènik et al. (2009) estudaram 846 acidentes florestais registrados na Eslovênia, entre os quais $68 \%$ se relacionaram com as operações de corte da árvore. A despeito da gravidade dos acidentes, indicada pelo número de dias de afastamento, relacionados à movimentação de veículos ou máquinas, os acidentes provocados pelo choque com partes das árvores, pedras, rochas e terreno de trabalho são os que determinam a maior perda de dias de trabalho. No entanto, contrariamente ao resultado mencionado, a motosserra foi associada com apenas $6 \%$ dos acidentes.

Em estudo recente, autores eslovenos sustentam que a mecanização no corte e na colheita está associada à diminuição da ocorrência de acidentes com a motosserra, tipo de lesão e região do corpo atingida (Potoènik et al., 2009). As mudanças são devidas ao deslocamento da incidência relacionada às atividades de produção propriamente dita, incluindo o corte com a motosserra, para as operações ligadas à preparação e manutenção da área a ser trabalhada, as quais dependem de veículos motorizados.

Outros estudos já registraram uma diminuição da incidência de lesões do tipo corte e laceração em regiões corporais, à medida que os equipamentos manuais foram sendo substituídos 
por máquinas com cabines, pois, entre outros fatores, reduziu-se o número de empregados expostos ao perigo potencial de motosserras (Lelfort et al., 2003).

Em suma, os riscos para os operadores florestais mudam de acordo com as inovações no setor. Outrora expostos predominantemente aos choques contra as árvores, na atualidade, o perfil das ocorrências evidencia acidentes relacionados as máquinas nos terrenos ou ao transporte da madeira. Nessa direção, Lelfort et al. (2003) sugerem estratégias de segurança do tipo global, de maneira a garantir a proteção do operador durante o movimento das máquinas e dos materiais.

Infelizmente, no Brasil, os acidentes são subnotificados e, quando os dados estão disponíveis, não são desagregados, dificultando a análise de acordo com as características da empresa, da região do corpo atingida, das operações envolvidas e do perfil do acidentado. Tal realidade é mais expressiva quando o emprego é precário.

Os efeitos da intensificação do trabalho, muito comum no ambiente de trabalho terceirizado, também afetam a segurança dos trabalhadores. $\mathrm{O}$ horário de trabalho e as longas jornadas diárias podem contribuir para a diminuição da vigilância, colocando em risco a segurança individual e coletiva. A raridade e a curta duração dos descansos agravariam os efeitos da jornada de trabalho excessiva (Lilley et al., 2002).

Danos físicos, como a perda auditiva induzida pelo ruído, estão associados à diminuição da capacidade de percepção de risco iminente de acidente (European Agency for Safety and Health at Work, 2008). Alterações músculoesqueléticas estão presentes e são associadas ao transporte manual de carga, como assinalado por Fiedler (2001), que estudou as operações de descascamento de madeira efetuadas por operadores em empresa florestal do estado da Bahia, identificando esforços físicos acima dos limites toleráveis. Em Minas Gerais, 41,4\% dos operadores de motosserra registraram episódios de lombalgia esporadicamente, os quais foram atribuídos às posturas adotadas na operação de der- rubada e no traçamento com a motosserra (Santana; Malinovski, 2002).

Nos Estados Unidos, em 2005, as taxas mais elevadas de mortalidade e de letalidade foram registradas na construção civil e no transporte, no setor que abarca atividades da agricultura, silvicultura e pesca. Em torno de 48 \% das mortes ocorreram em situações de transporte. Na sequência, estão os acidentes originados do choque com objetos e equipamentos e, entre eles, cita-se a derrubada de árvores (USA/CDC, 2007).

Na Espanha, entre 2000 e 2002, o setor extrativista liderou o ranking de acidentes de trabalho não-fatais, alcançando a proporção de 222,9 casos de acidentes por 1.000 segurados; em segundo lugar, na construção civil, com 169,2 por 1.000; e, em terceiro, a indústria manufatureira, que atingiu 94,1 por 1.000. Quanto aos acidentes fatais, as taxas de incidência, segundo o ramo produtivo, foram as seguintes: pesca, 103,3 por 100 mil segurados; indústria extrativa, 35,9; transporte, 25,5; e a construção, com uma incidência de 19,8 (Benavides et al., 2006).

Em relação às lesões por acidentes de trabalho, as operações florestais na Nova Zelândia são consideradas de alto risco, quando comparadas àquelas realizadas em outros setores produtivos. Entre as operações, a colheita das árvores é a mais crítica. Em 2000, 389 acidentes foram registrados, 121 com perda de dias de trabalho, totalizando uma incidência de acidentes com perda de tempo de 14 por 1 milhão de horas trabalhadas, cifra inferior à dos anos anteriores: (1) em 1998, 17 por 1 milhão de horas trabalhadas; (2) em 1999, 20 por 1 milhão de horas trabalhadas (Bentley et al., 2005). Os maiores riscos, segundo os autores, estão presentes nas operações de derrubada das árvores, manejo da motosserra e de máquinas para o transporte dos materiais.

De acordo com as informações da Previdência Social para 2003, os maiores coeficientes de mortalidade por acidentes de trabalho no Brasil foram observados no setor de transporte, seguido pelo setor extrativista mineral e, em terceiro lugar, pela indústria da construção. Vê-se, 
assim, que o setor extrativista vegetal não aparece entre os setores em destaque para os acidentes fatais, segundo as fontes consultadas. No entanto, vale mencionar a fragilidade das estatísticas sobre acidentes de trabalho em virtude da reconhecida magnitude da subnotificação (Santana et al., 2005).

\section{TERCEIRIZAÇÃO E INSEGURANÇA NO TRABALHO}

No Brasil, a terceirização na área florestal está presente em quase todas as empresas do setor. Há registro da presença de serviços terceirizados em $70 \%$ dos serviços florestais (Morais Filho; Seixas, 2009). Em Minas Gerais, o caso estudado por Camara (2004) ilustra o crescimento da terceirização. Em 1998, essas empresas foram responsáveis por 9\%, passando, em 2001, para um percentual de $34 \%$ do total da produção florestal realizada na região. Paralelamente, ocorreu um aumento da mão de obra contratada temporariamente. Sendo usadas como uma opção para redução do custo das atividades, as terceiras estão presentes desde o plantio até a colheita, passando por todas as etapas do manejo florestal.

O foco da terceirização dirige-se para a colheita da árvore, fase mais perigosa e onerosa. Se apenas trabalhadores do quadro da empresa contratada atuam na colheita do tipo manual, os riscos de acidentes fatais presentes no corte e na derrubada de árvores, durante atividade manual com a motosserra, suficientemente descritos na literatura disponível, dizem respeito apenas aos trabalhadores terceirizados.

A tendência de aumento das taxas de acidentes, quando se trata de terceirização, é atribuída não somente à transferência selecionada de riscos, mas também à transferência das responsabilidades e da efetivação de medidas de segurança para a empresa terceirizada. No entanto, a empresa terceirizada (e seus contratos temporários) investe pouco na formação do trabalhador, limita o treinamento em segurança, negligencia as zonas críticas de trabalho, acresce exigências de produtividade, restringe o fornecimento ou a adequação dos equipamentos de proteção individual (European Agency for Safety and Health at Work, 2002).

A referida situação talvez explique por que, na Espanha, a incidência de acidentes entre os trabalhadores com contratos permanentes $(44,9$ por 1000 em 2002) foi inferior à taxa encontrada no grupo dos trabalhadores com contratos temporários (120,6 por 1000 em 2002), indicando uma proporção três vezes maior para os últimos (Benavides et al., 2006).

As operações consideradas de risco necessitam de grandes investimentos em treinamento, em recursos humanos e em monitoramento. Assim, conforme foi enfatizado, as operações de risco são transferidas para outras empresas que oferecem margens ainda mais estreitas para a qualificação e enfrentam menos poder de negociação dos seus trabalhadores, geralmente contratados temporariamente.

Vê-se, assim, como as mudanças nos padrões de emprego, que explicam posições diferenciadas na ocupação, afetam a regulação das regras organizacionais, como também das regras jurídicas, em especial aquelas do direito do trabalho. Trata-se da já mencionada desregulamentação do Estado sobre o trabalho e das mudanças que têm ocorrido nas relações de assalariamento (Thébaud-Mony; Druck, 2007; Rivero, 2009).

Ademais, nesse contexto, as regras de segurança são flutuantes. Exemplificando, a distância mínima entre uma equipe de corte e outra, em 1991, era estabelecida em 60 metros e diminuiu para 40 metros, em 1997, e, atualmente, é de 30 metros! Paralelamente, modificaramse as condições de trabalho no que diz respeito às suas formas de organização e de controle, implicando novas exigências, por exemplo, o comprimento dos toretes.

Canto et al. (2007) estudaram as condições de segurança do trabalho em 90 situações estabelecidas por meio de contrato entre uma empresa florestal e proprietários rurais do estado do Espírito Santo, que se encontravam em processo 
de colheita e transporte da madeira. Os autores citam que o desgalhamento foi executado com motosserras em 70,5\% dos casos; com instrumentos manuais (machados e facões) em 10,0\% deles; e de forma desconhecida pelos proprietários em 19,5\% dos casos. Saliente-se que 73\% dos proprietários não fizeram exigência alguma na contratação da mão de obra. $\mathrm{O}$ restante exigiu experiência, mas não solicitou comprovação.

O exame das precárias condições de trabalho que motivaram a criação da CPI em Minas Gerais trouxe à tona os métodos de gestão vigentes nas empresas implicadas que estavam relacionadas com as operações florestais. Camara (2004), ao examinar os documentos dessa CPI, evidencia associação clara entre a prática da terceirização e a deterioração das condições de trabalho no setor:

... as empresas investigadas, a maioria de grande porte - algumas multinacionais -, que contam com estrutura apropriada na área de segurança $e$ medicina do trabalho, não podem propagar a terceiros suas obrigações sociais, mormente a pequenos empresários e a microempresas, como se verificou na maioria dos casos investigados, sob risco de proporcionar condições de trabalho altamente arriscadas e enorme agravante à saúde dos empregados (ALMG, 2002).

Os relatos colhidos na ALMG associam os acidentes às condições geradas, em grande parte, pela inserção da empresa contratada na atividade de produção da grande empresa (contratante). Esses aspectos da demanda são reproduzidos nos depoimentos das lideranças sindicais durante a CPI:

... os trabalhadores são expostos a situações degradantes, enquanto os patrões centram a sua atenção apenas nos lucros sem preocupação com a saúde, a integridade física dos seus trabalhadores.

Há situações inusitadas, que revelam a tolerância social diante de situações extremas. Citase o caso do uso de transporte animal, por conta e risco do trabalhador contratado, para o deslocamento da madeira. Extraiu-se do Relatório da CPI o seguinte relato:

... uma empreiteira de uma grande indústria de papel, situada no estado de Minas Gerais, subcontrata trabalhadores para o transporte de madeira onde o local de plantação é de difícil acesso. O subcontratante tem que ter um animal (um burro) para fazer o transporte da madeira. A empresa não fornece local para guarda do animal. O tempo de trabalho de busca e apreensão do animal é penoso e muito demorado. Há dias em que o operário não trabalha por não ter pegado o burro (ALMG, 2002).

Chama a atenção a utilização do termo “coopergatos”, em referência às cooperativas que contratam voluntários para o trabalho temporário. O termo "gato" designaria esse tipo de cooperativa, a qual seria caracterizada, nos dizeres da FTIEMG, por "falsas cooperativas de produção e trabalho [...]. Assim, temos trabalhadores em empresas que cumprem o mínimo previsto na legislação trabalhista sem nenhum benefício social” (ALMG, 2002).

A Federação dos trabalhadores do setor (FTIEMG) denuncia o descumprimento da legislação trabalhista e os efeitos da terceirização, que desdobraria em "quarteirização" (referindose à subcontratação em cascata), como explicita um sindicalista:

... o descumprimento da CLT não ocorre só nas pequenas empresas; a terceirização é um fator importante na história recente da categoria e no reflorestamento, uma vez que a quase totalidade dos trabalhadores estão terceirizados ou quarteirizados e são contratados por empresas prestadores de serviço e não são donas do negócio.

A CPI concluiu, ao final dos seus trabalhos, que: (1) as empresas do setor fogem das responsabilidades trabalhistas; (2) há desrespeitos às normas jurídicas do país (legislação celetista e constitucional); (3) há diferenças de comportamento entre as empresas terceirizadas e aquelas que as contratam: nas terceirizadas, uma vez que os salários são sempre menores, os trabalhadores terceirizados trabalham lado a lado com contratados diretos, executando tarefas, mas com remuneração menor; a terceirização aumenta os riscos de acidentes de trabalho e de doenças, bem como enfraquece a representação dos trabalhadores pelos sindicatos, como se lê nos arquivos:

... as grandes empresas do setor extrativista investigadas, de acordo com a comissão, transfe- 
rem atribuições e riscos para as terceirizadas, geralmente empresas de ex-empregados, que não têm condição de arcar com a responsabilidade que assumem (ALMG, 2002).

Vê-se, assim, com a transferência de "atribuições e riscos”, reproduzir-se a insegurança no ambiente de trabalho, quando as empresas decidem transferir o risco, ao invés de adotar medidas efetivas de prevenção. Socialmente enfraquecidos, os trabalhadores "aceitam" correr riscos que eles mesmos conhecem, gerando um ambiente estressante (Camara, 2007).

Práticas inseguras surgem de mudanças na organização do trabalho, ao provocarem a redução de quadros e intensificar o trabalho. Mencionam-se casos de os próprios trabalhadores bloquearem os sistemas de segurança das máquinas (prensas, por exemplo) para induzir produção ininterrupta, quando as metas são apertadas (Papadopoulos et al., 2010).

$\mathrm{Na}$ indústria florestal, os trabalhadores admitem quebrar regras de segurança diante da pressão temporal no cumprimento das metas. Exemplificando, para derrubar uma árvore segundo a prescrição habitual, são necessários 14 minutos; usando métodos inseguros, o tempo seria reduzido para um a quatro minutos (Camara, 2004). Como lidar com essa realidade? Certamente, medidas tradicionais no campo da segurança ocupacional são insuficientes, como bem atestam estudos realizados em outros setores (Diniz et al., 2005; Chapman; Husberg, 2008).

Os modelos de remuneração podem acentuar o clima de insegurança. Os especialistas da empresa contratante estudada por Camara (2004) estipulam previamente, em cada projeto florestal, os parâmetros de produtividade. Por área, determina-se o volume de árvores por metro cúbico, de árvores por metro estéreo e o número de árvores a ser derrubado por cada trabalhador, a cada jornada de trabalho. Trata-se da meta de produção diária. A produção da equipe pode chegar até a 180 árvores por dia, implicando tarefas de derrubar, desgalhar e traçar a árvore.

Essa empresa também mantém uma polí- tica de remuneração por excedente de produção da meta. Por meio de abono, gratificam-se financeiramente aqueles trabalhadores que obtiveram uma produtividade em metros estéreos acima da sua média mensal (obtida em 21 dias de trabalho no mês). Para cada estéreo unitário produzido acima da meta, o trabalhador recebe o valor de um real.

Quanto às metas de produção, sabidamente relacionadas à segurança, segundo os depoimentos colhidos na CPI de Minas Gerais, nos últimos dois anos, as empresas aumentaram em 55 centímetros a medida prevista para os toretes, passando de $2 \mathrm{~m} 05$ para $2 \mathrm{~m}$ 60, sem considerar os agravos à saúde do aparelho musculoesquelético associados ao manejo de cargas (ALMG, 2002). No âmbito da atividade de trabalho, essa diferença não é banal. Mas a concepção que orienta as decisões não é determinada pelas potencialidades do trabalho nem dos trabalhadores. Ao contrário, segue critérios financeiros e nem sempre razoáveis no âmbito da segurança.

As vicissitudes do meio (características climáticas, condições do terreno, proximidade de outras equipes) não são contabilizadas quando a gestão estipula a meta diária. O discurso de um trabalhador entrevistado por Camara (2004) é enfático quanto aos inúmeros fatores aleatórios que interferem nas operações, gerando zonas de insegurança. Segundo ele:

Por causa do terreno... A madeira cai no buraco, agarra o buraco... Às vezes, a madeira cai para um lado e você queria jogar para outro. Se ele pegar um terreno igual ao que você mostrou aí, ele vai demorar a tirar essa meta, sabe. Num dia não sai. (Operador. Entrevista em autoconfrontação).

Quanto à exigência de produtividade, existe uma associação entre o aumento da gravidade de lesões e a vigência de pagamento por unidades de árvores derrubadas. Os autores explicam que os trabalhadores expõem-se mais frequentemente aos riscos quando ganham por produção de árvores derrubadas. Para Sundstrom-Frisk (1984), a taxa de acidentes é menor no grupo dos trabalhadores assalariados, se comparada ao grupo dos trabalhadores que recebem por pro- 
dução, devido às margens existentes no primeiro caso para o desenvolvimento de formas de cooperação. Exemplificando: é possível o colega interromper o trabalho para ajudar o outro que se depara com árvores "enroscadas". No caso de pagamento por produção, a estratégia levaria à "perda" de tempo e de ganhos.

As regiões de trabalho, denominadas "pegas", são distribuídas às equipes pelos organizadores da produção. Entre os trabalhadores, são conhecidas as expressões: "pega boa" ou "pega ruim". A "pega" é uma divisão da região, delimitada pela empresa, que será trabalhada pelo conjunto das equipes. Em cada "pega” ficam dois trabalhadores. As "pegas" são mensuradas pelos organizadores, os quais se utilizam de medidas geométricas para estimar a produtividade. Vale mencionar que as características das "pegas", como relevo e tipo das copas das árvores, são fortes determinantes da carga de trabalho e das zonas críticas para a segurança.

Os organizadores da produção sorteiam a região a ser destinada a cada equipe, desvencilhando-se de acusações de favorecimento de uma equipe em detrimento de outra. O sorteio de "pegas" é a manifestação de uma política de segurança cruel e ineficaz. Ao invés de treinar e fortalecer, com equipamentos e recursos, as equipes a serem destinadas às regióes com maior potencial de acidentes, utiliza-se um procedimento que, declaradamente, expõe os indivíduos às fatalidades do destino. As equipes sem experiência para enfrentar as situações de variabilidade ficam sujeitas a lidar com zonas complexas. Mais uma vez, colocam-se as desvantagens para os trabalhadores terceirizados, pois, com menos chance de fixação na empresa e de treinamento específico, estarão menos equipados para o enfrentamento de tais zonas. Fica claro que os organizadores da produção reconhecem o risco, mas não elaboram medidas de proteção ou de controle, deixando ao acaso a solução do problema.

Por fim, ressalta-se que, independentemente do setor, os trabalhadores terceirizados ou sob contratos temporários frequentemente são menos livres para escolher o período de suas fé- rias e, raramente, são representados nos comitês de saúde. Além disso, ocupam funções com menor exigência de habilidade e experimentam pior resultado de saúde, quando comparados aos trabalhadores permanentes. Sabe-se, também, que dispõem de menos informação sobre o seu ambiente, usufruem de menos autonomia e controle sobre os horários, quando comparados aos colegas empregados sob vínculo permanente (Buffet; Priha, 2009).

Empregos precários, muitas vezes, são caracterizados por horários de trabalho extremos, deficiências na segurança, baixos salários, maior exposição a riscos e condições estressantes. O inquérito realizado por Benavides et al. (2000), em 15 países da Europa (15.146 empregados), investigou a associação entre vários tipos de emprego e três fatores relacionados à saúde autorrelatados: insatisfação no trabalho, estresse, absenteísmo relacionado à saúde. Pesquisou-se, também, a associação entre vários tipos de emprego e três problemas de saúde autorrelatados: fadiga geral, lombalgia e dores musculares.

Os resultados evidenciaram associação positiva entre emprego e insatisfação no trabalho, mas negativamente associado ao absenteísmo e ao estresse, se comparados com os dos respondentes que relataram emprego sob contrato permanente. Fadiga geral, lombalgia e dores musculares foram positivamente associadas ao emprego precário. Entre os pequenos proprietários, constatou-se alta prevalência de estresse e de fadiga, mas o absenteísmo encontrado foi relativamente baixo. No conjunto, as variáveis socioeconômicas e regionais não foram suficientes para modificar a relação entre emprego (tipo de vínculo ou contrato) e os resultados de saúde, evidenciando o peso dessa relação.

\section{CONSIDERAÇÕES FINAIS}

A estratégia de buscar apoio em conhecimentos disponíveis na literatura científica e em registros sistematizados nos relatórios de agências (nacionais e internacionais) mostrou-se vantajosa, 
tendo em vista a análise documental que foi articulada ao estudo de caso de Camara (2004). Os elementos apresentados permitiram alcançar patamares elucidativos no tocante às características do emprego e os acidentes a elas relacionados.

Os dados da literatura mencionados expressam a contradição entre, de um lado, a nítida expansão da produção e, de outro, a precariedade das condições de trabalho. Zonas críticas destinadas a terceiros, pagamento por produtividade e sorteio das regiões difíceis são dimensões do emprego precário no setor estudado, explicando, de acordo com as evidências descritas, a distribuição dos acidentes.

Determinantes macroeconômicos explicam a lógica da terceirização e sua tônica nos contratos temporários. Em sua reestruturação, o mercado caracteriza-se por uma espécie de volatilidade, aumento da competição e do estreitamento das margens de lucro. Tendo em vista o enfraquecimento do poder sindical e o desemprego, o ambiente torna-se propício para contratos de trabalho mais flexíveis e precários (Harvey, 1994). Realidades e situações de trabalho são marcadas pelos efeitos do contexto de precarização do emprego. Entre os casos apresentados, destacam-se os de proprietários que contratam uma empresa para executar exclusivamente (e sem as condições necessárias) o corte com motosserra, operação reconhecidamente perigosa.

As situações determinadas pelo contexto de precarização do emprego favorecem o bloqueio das iniciativas de atenuação dos riscos, mostrando, ademais, uma tolerância com os comportamentos considerados inseguros. Ao invés de proceder à elaboração de estratégias de prevenção baseadas nos conhecimentos dos trabalhadores, a gestão da colheita das árvores prefere "sortear" as regiões perigosas entre as equipes.

Lacunas na formação para executar as tarefas e deficiências nas máquinas e ferramentas também são atributos do trabalho terceirizado e coincidem com os fatores de risco de acidentes. A permanência temporária em uma empresa (característica da terceirização) impede o conheci- mento da área e enfraquece os coletivos de trabalho, ambos fundamentais para a elaboração de estratégias de enfrentamento do risco (De La Garza; Poy, 2009).

As margens para uma tomada de decisão baseada no saber-fazer construído ao longo de sua experiência de trabalho são estreitas, gerando barreiras para a elaboração de estratégias de autoproteção. De acordo com Chapman e Husberg (2008), o planejamento e o método de derrubada de árvores, dependentes da formação e experiência do operador, são mais importantes do que as medidas clássicas de segurança para prevenir o acidente.

Pela dificuldade de construir vínculos, os trabalhadores terceirizados estão menos habilitados para avaliar o terreno, o traçado das copas das árvores, a direção do vento, a força ou a distribuição do peso de uma árvore. Todas essas situações, com a experiência, conformariam indícios do risco de o operador, por exemplo, ser atingido por uma árvore em derrubada. Dito de outra forma, os acidentes estão também associados à qualidade das decisões (com desvantagens para os trabalhadores terceirizados), que dizem respeito às árvores que cairão em primeiro lugar, o tipo de corte e em que direção se planeja derrubar a árvore. O planejamento inclui também a determinação de uma rota de escape adequada ao longo da qual o operador e o seu ajudante poderão se deslocar.

Em síntese, a prevenção de riscos requer julgamento, incluindo tanto a percepção e a antecipação do risco quanto as condições para a tomada de decisão baseada em sua formação, experiência, conhecimentos e, fundamentalmente, recursos, num ambiente organizacional no qual produtividade e segurança sejam dimensões igualmente consideradas na gestão da produção. No conjunto, tais dimensões são inviáveis no atual quadro do emprego precário no setor florestal.

Inúmeros programas preventivos desenvolvidos mundialmente alcançaram resultados muito limitados. Em geral, a elaboração de políticas para o setor tende a excluir a participação 
dos trabalhadores, proprietários e gestores de pequenas empresas. Para ultrapassar barreiras, Chapman e Husberg (2008) indicam disseminar informação ao alcance dos trabalhadores e de seus sindicatos, e também para as organizações industriais. Entre as medidas que visam a mudanças do paradigma da prevenção, destaca-se o treinamento de chefias imediatas e de outros atores das pequenas empresas, com vistas a promover o empoderamento necessário para a tomada de decisões implicadas na segurança florestal.

De acordo com as reflexões trazidas pelos pesquisadores e profissionais da área, será necessário e urgente, elaborar estratégias intersetoriais a fim de intervir não apenas nas condições de trabalho (nível micro), mas, fundamentalmente, atingir as políticas públicas de emprego e a economia no plano global.

(Recebido para publicação em 07 de outubro de 2010) (Aceito em 06 de abril de 2011)

\section{REFERÊNCIAS}

ALMG. Assembléia Legislativa de Minas Gerais. Comissão Parlamentar de Inquérito sobre as condições de trabalho nas carvoarias. Belo Horizonte, 2002. Relatório final.

ANTUNES, R. Dimensões da precarização estrutural do trabalho. In: FRANCO T.; DRUCK G. A perda da razão social trabalho: terceirização e precarização. São Paulo:

BENAVIDES, F. G. et al. How do types of employment relate to health indicators? Findings from the Second European Survey on Working Conditions. Journal Epidemio Community Health, Washington,DC,v.54, p.494-501, 2000. papel. 2010. Disponível em: www.bracelpa.org.br/bra/ estatisticas/pdf/ booklet/booklet.pdf. Acesso em: 15 set. 2010.

BUFFET, M-A.; PRIHA, E. Workforce diversity and risk assessment - Ensuring everyone is covered. European Agency for Safety and Health at Work, Belgium, 2009. Disponível em: osha.europa.eu/en/ publications/reports/ TE7809894ENC. Acesso em 27 ago. 2010.

CAMARA, G. R. O saber prático dos trabalhadores florestais para evitar acidentes do trabalho durante o corte de madeiras com motosserras. 2004. Dissertação (Mestrado) Faculdade de Medicina da Universidade Federal de Minas Gerais. Belo Horizonte, 2004.

; ASSUNCÃO, A. A., LIMA, F. P. A.Os limites da abordagem clássica dos acidentes de trabalho. Revista Brasileira de Saúde Ocupacional, São Paulo, v.32, n.115, p.4151, 2007.

CANTO, J. L. et al. Avaliação das condições de segurança do trabalho na colheita e transporte florestal em propriedades rurais fomentadas no Estado do Espírito Santo. Revista Árvore, Viçosa,MG, UFV, v.31, n.3, p. 513-52, 2007.

CARVALHO, R. M. M. A., SOARES, T. S., VALVERDE, S.R. Caracterização do setor florestal: uma abordagem comparativa com outros setores da economia. Ciência Florestal, Santa Maria,RS, CEPEF, v. 15, n. 1, p.105-118, 2005.

CASTEL, R. As armadilhas da exclusão. In: BÓGUS, L.; YAZBEK, M.C.; BELFIORE-WANDERLEY, M. (Org.) Desigualdade e a questão social. São Paulo: Editora Educ, 1997. p.15-48,

CHAPMAN, L. J.; HUSBERG, B. Agriculture, forestry, and fishing sector. Journal of Safety Research, New York, v.39, n.2, p.171-173, 2008.

DE LA GARZA, C.; POY, M. Seguridad y salud laboral, seguridad industrial: desafíos de un enfoque de prevención sustentable. Laboreal, Porto Pt, Universidade do Porto, v.5, n.1, p.95-105, 2009.

DINIZ, E. P. H., ASSUNCÃO, A. A.; LIMA, F. P. A. Prevenção de acidentes: o reconhecimento das estratégias operatórias dos motociclistas profissionais como base para a negociação de acordo coletivo. Ciência \& Saúde Coletiva, Rio de Janeiro, v.10, n.4, p.905-916, 2005.

EUROPEAN AGENCY FOR SAFETY AND HEALTH AT WORK. Occupational safety and health in Europe's forestry industry. E-facts 29, 2008. Disponível em: osha.europa.eu/ en/ publications/e-facts/efact29. Acesso em: 03 set. 2010.

. New forms of contractual relationships and the implications for occupational safety and health. Luxembourg. Office for Official Publications of the European Communities, 2002.

FABIANO, D. et al. Statistical study on temporary work and occupational accidents: s;ecific risk factors and risk management strategies. Safety Science, New York, v.46, p.535-544, 2008.

FIEDLER, N. C. Avaliação dos limites recomendados de pesos de toras manuseadas em atividades de descascamento de madeira. Ciência Florestal, Santa Maria,RS, v.11, p.1-8, 2001.

GALEAZZI, I. M. S. O trabalho por conta própria num contexto de precarização laboral. In: BASTOS, R. L. A. (Org.) Dimensões da precarização do mercado de trabalho na Região Metropolitana de Porto Alegre. Porto Alegre: Fundação de Economia e Estatística, 2007. p.81-151,

HARVEY, D. Condição pós-moderna: uma pesquisa sobre as origens da mudança social. São Paulo: Ediçõ̃es Loyola, 1994.

LEFORT JR., A. J. et al. Characteristics of injuries in the 
logging industry of Louisiana, USA: 1986 to 1998. International Journal of Forest Engineering, Madison,USA, v.14, n.2, p.75-79, 2003.

LILLEY, R. et al. A survey of forest workers in New Zealand. Do hours of work, rest, and recovery play a role in accidents and injury? Journal of Safety Research, New York, v.33, p.53-71, 2002 .

MORAIS FILHO, A. D.; SEIXAS, F. Análise técnica e econômica de prestadores de serviços na colheita florestal. $C i$ ência Florestal, Santa Maria,RS, v.19, n.1, p.99-108, 2009.

PAPADOPOULOS G. et al. Occupational and public health and safety in a changing work environment: An integrated approach for risk assessment and prevention. Safety Science, New York, v.48, n.8, p.943-949, 2010.

POTOĖNIK, I.; PENTEK T.; POJE, A. Severity analysis of accidents in forest operations. Croation Journal of Forest Engineering, Los Angeles,USA, v.30, n.2, p.171-184, 2009.

RIVERO, P. Trabalho: opção ou necessidade? Um século de informalidade no Rio de Janeiro. Belo Horizonte: Editora Argvmentvum, 2009.
SANTANA, V.; NOBRE L.; WALDVOGEL, B. C. Acidentes de trabalho no Brasil entre 1994 e 2004: uma revisão. Ciência \& Saúde Coletiva, Rio de Janeiro, v.10, n.4, p.841-855, 2005.

STREHLKE, B., Forest Management: employment, working conditions and occupational safety. Unasylva, Los Angeles, v.44, n.172, p. 25-30, 1993

SUNDSTROM-FRISK, C. Behavioral control through piecerate wages. Journal of Occupational Accidents, New York, v.6, p.49-59, 1984

THÉBAUD-MONY A., DRUCK, G. Terceirização: a erosão dos direitos dos trabalhadores na França e no Brasil. In: FRANCO, T.; DRUCK, G. A perda da razão social do trabaIho: terceirização e precarização. São Paulo: Boitempo Editorial, 2007. p.23-58,

USA. United States of America/CDC. Centers for Disease Control and Prevention. Fatal Occupational Injuries: United States, 2005. Journal of American Medical Association: Jama, [S.l.] v.297, n.20, p.2193-2194, 2007. 


\section{LABOR PRECARIZATION AND PRODUCTION OF ACCIDENTS IN HARVESTING OF TREES}

\author{
Ada Ávila Assunção \\ Guilherme Ribeiro Camara
}

The forestry industry has the highest rates of labor-associated mortality in the world, despite the introduction of mechanization in the sector. In this paper, we studied the documents of the Parliamentary Commission of Inquiry instituted to check fatal accidents occurred in Minas Gerais. We analyzed the process of work done by teams of a logging company and found that the accumulated knowledge about the risk factors for accidents in this sector did not guide the transformation of work situations. The time of the felling of trees and the consequent risk of being "struck by" are the main causes of accidents and prompted the study, which is consistent with the description found in the literature. The precarious employment relationships predominate in the sector. The authors associate the continuing exposure to risks to increased outsourcing, focused on the stages of production, recognized as dangerous.

KEYwords: extractivism, industrial accidents, precarization, workers' health.

\section{LA PRÉCARISATION DU TRAVAIL ET LA PROVOCATION D'ACCIDENTS DANS LA CUEILLETTE DES ARBRES}

\author{
Ada Ávila Assunção \\ Guilherme Ribeiro Camara
}

C'est dans l'industrie forestière que l'on trouve les plus hauts taux, à niveau mondial, de mortalité associée au travail bien que le secteur ait été mécanisé. Cet article présente une étude faite à partir des documents de la Commission d'Enquête Parlementaire instituée pour vérifier les accidents mortels survenus dans l'État de Minas Gerais. Une analyse du processus du travail, réalisée par les équipes chargées de la coupe des arbres d'une entreprise d'extraction forestière, $y$ est faite et on a pu constater que les connaissances accumulées sur les facteurs de risques d'accidents dans le secteur n’ont pas permis la transformation de la réelle situation de travail. Le moment de l'abattage des arbres et, par conséquent, les risques d'être « atteint par » sont les principales causes d'accidents correspondant aux descriptions trouvées dans la littérature. C'est pourquoi une étude a été sollicitée. Des relations précaires de travail prédominent dans ce secteur. Les auteurs associent le maintien de cette situation d'exposition aux risques pour les travailleurs à une sous-traitance croissante qui, dans les phases de production reconnues dangereuses, augmente encore plus.

Mots-CLÉs: extraction, accidents de travail, précarisation, santé du travailleur.

Ada Ávila Assunção - Médica. Doutora em Ergonomia. Professora Associada na Faculdade de Medicina da UFMG. Coordenadora da Rede Latino-Americana de Atenção à Saúde dos Trabalhadores da Saúde. Realiza trabalhos de consultoria para instituições públicas e organizações de trabalhadores no tocante à formação em metodologias de intervenção em ambientes e condições ergonômicas de trabalho. Publicações recentes: Prevalence of Musculoskeletal Disorders among Plastics Industry Workers. Cadernos de Saúde Pública (ENSP. Impresso), v. 27, p. 78-86, 2011; Prevalência e fatores associados ao Transtorno de Estresse Pós-Traumático (TEPT) em profissionais de emergência: uma revisão sistemática da literatura. Revista Brasileira de Epidemiologia (Impresso), v. 14, p. 217-230, 2011; Quality of Life, Self-Perceived Dysphonia, and Diagnosed Dysphonia Through Clinical Tests in Teachers. Journal of Voice, v. 25, p. 192-201, 2011.

Guilherme Ribeiro Camara - Médico do trabalho. Mestre em Saúde Pública. Coordenador de Medicina do Trabalho na Fundação São Francisco Xavier/Hospital Márcio Cunha, Ipatinga, MG. Tem experiência na área de Saúde Coletiva, com ênfase em Saúde do Trabalhador, atuando principalmente nos seguintes temas: saúde, trabalhador, dados, sistema e informação. Publicações: Os limites da abordagem clássica dos acidentes de trabalho: o caso do setor extrativista vegetal em Minas Gerais. Revista Brasileira de Saúde Ocupacional, v. 32, p. 41-51, 2007; Percepção social dos problemas relacionados com o uso dos sistemas de informação em saúde do trabalhador no Sistema Único de Saúde (SUS). IP. Informática Pública, Belo Horizonte, v. 3, n. 1, p. 111-126, 2001. 